\title{
A (Visual) Novel Route to Learning: A Taxonomy of Teaching Strategies in Visual Novels
}

\author{
Janelynn Camingue \\ University of California, Santa Cruz \\ Santa Cruz, CA \\ jcamingu@ucsc.edu
}

\author{
Edward F. Melcer \\ University of California, Santa Cruz \\ Santa Cruz, CA \\ eddie.melcer@ucsc.edu
}

\author{
Elin Carstensdottir \\ University of California, Santa Cruz \\ Santa Cruz, CA \\ ecarsten@ucsc.edu
}

\begin{abstract}
Interactive narratives are widely used to frame and contextualize education in games. However, the specifics of how their designs aid the learning process and outcomes remains relatively unexplored. To better understand this space, a study was conducted that focused on one sub-genre of interactive narrative, Visual Novels. Specifically, in this paper we conducted a survey of thirty-one existing educational Visual Novels, analyzing design elements that fostered learning and delivered educational content. The resulting taxonomy consists of five key dimensions for educational design and teaching strategies within Visual Novels: 1) Teaching Through Choice, 2) Teaching Through Scripted Sequences, 3) Teaching Through Mini-games, 4) Teaching Through Exploration and 5) Non-interactive Teaching. These dimensions demonstrate that there are a number of design considerations for supporting learning through Visual Novels. This work has implications for designers of educational games by classifying the different designs a Visual Novel can employ to teach-ultimately informing how to better present educational subject matter in interactive narrative games.
\end{abstract}

\section{CCS CONCEPTS}

- Applied computing $\rightarrow$ Interactive learning environments; - Human-centered computing $\rightarrow$ Human computer interaction (HCI); HCI theory, concepts and models.

\section{KEYWORDS}

Visual Novels, Interactive Narratives, Educational Design, Educational Games, Taxonomy

\section{ACM Reference Format:}

Janelynn Camingue, Edward F. Melcer, and Elin Carstensdottir. 2020. A (Visual) Novel Route to Learning: A Taxonomy of Teaching Strategies in Visual Novels. In International Conference on the Foundations of Digital Games (FDG '20), September 15-18, 2020, Bugibba, Malta. ACM, New York, NY, USA, 13 pages. https://doi.org/10.1145/3402942.3403004

\section{INTRODUCTION}

Visual Novels (VNs) are a sub-genre of interactive narratives, which are a form of interactive experiences where users can create or impact a storyline through certain actions [104]. VNs are widely used

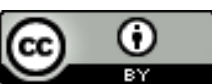

This work is licensed under a Creative Commons Attribution International 4.0 License.

FDG '20, September 15-18, 2020, Bugibba, Malta

(C) 2020 Copyright held by the owner/author(s).

ACM ISBN 978-1-4503-8807-8/20/09.

https://doi.org/10.1145/3402942.3403004 for educational purposes both within academia $[1,4,7,8,10,57,98$, 128] and industry [28]. These games cover a broad range of topics from fictional languages [10] to self-efficacy in programming [2]. Part of the widespread popularity of VNs for education is due to the accessibility the genre provides, with a low demand on player actions, focus on storytelling, and role-playing elements all helping to engage a larger audience [128]. There are also a substantial number of VN development tools-such as Novelty [57], Unity [98], and Ren'Py[4]-which support ease of development for educational game designers at a wide variety of technical skill levels. Notably, educational VNs have often been developed in academic settings as alternatives to traditional non-interactive text and reading materials, e.g., $[48,51,94]$, with many arguing for their potential as powerful learning tools [87, 104, 123].

Despite this apparent advantage, educational VNs are understudied in terms of their educational effectiveness (see Related Work), and many educational VN designs have not been demonstrably successful at integrating educational content delivery and an interactive narrative experience. This stems from a lack of research focus both on interactive narrative design as a whole [26], as well as on the underlying interaction design and mechanics supporting delivery of educational content. This could cause a variety of potential problems, such as preventing or distracting the player from learning by introducing design elements or story content that is incompatible with the learning process/content-resulting in extraneous cognitive load [118]. One example of how design choices can conflict with educational outcomes is seen in many current VNs, where educational content delivery is not incorporated directly into the mechanics underlying VN elements (which is critical for good educational game design [103]) and introduces unnecessary confounds for the player as a result. For instance, in the educational VN Artificial Tomodachi [6], narrative and choices given to the player are unrelated to the educational content of the game-ultimately separating the act of learning from the act of playing [84, 126].

One way to address the lack of research and ambiguity around interaction design and mechanics supporting the delivery of educational content is through the creation of a taxonomy [90]. A taxonomy is a popular tool that provides a common language for designers and researchers to discuss design knowledge, classify new and existing designs, generate prototypes, formulate research questions, and conceptualize empirical studies [17, 20]. With respect to games, taxonomies have commonly been utilized to provide classifications of game genres [14, 101], design choices [33, 88, 90], and even games themselves $[12,43]$. As a result, a taxonomy at the intersection of VNs and education would provide structure to classify and formalize the design decisions and teaching strategies underlying educational VNs. 
In this paper, we present a taxonomy of teaching strategies identified in existing educational VNs, which was built using thematic analysis of 31 educational VNs. In particular, our analysis focused on the different strategies for educational content delivery as it relates to narrative progression, a central concern for interactive narrative [26], as well as narrative structure and diegetic/non-diegetic feedback. We also discuss each category in detail and the specifics of how each strategy was implemented in existing games. Finally, we discuss the design implications the strategies pose for VNs, examine their potential teaching efficacy from the perspective of existing literature on learning, and discuss how notable design elements of the VN genre are utilized for educational VNs. As such, this work has broader implications for understanding and improving current interactive narrative work and use of narrative for educational content delivery outside the genre.

\section{RELATED WORK}

Educational games have employed narrative in a variety of ways to support and enhance learning, such as being a framing device and tool to contextualize and motivate learning [107]. In this section, we discuss the manner in which educational games have utilized narrative as a part of their design, and how such designs can be described and captured-focusing on structure, progression, and diegesis. Existing explorations of educational interactive narratives, especially educational VNs, and their potential impact on learners are also reviewed.

\subsection{Narrative in Educational Games}

2.1.1 Educational Interactive Narratives. Interactive narrative, in the form of narrative games, is defined as games where the story exists to enhance game play [111]. There has been a number of works suggesting the potential for interactive narrative/storytelling in improving education [34, 59, 87, 104, 123], and prior work has found a substantial positive impact from adding narrative/storytelling to educational games in order to maintain or increase students' motivation [30, 39, 102, 110]. However, there is still a surprisingly limited amount of work evaluating the efficacy of such games on learning outcomes, especially when compared to other genres of educational games [24, 65, 91], with the few notable exceptions being $[80,89,92,110,122,124,131]$. The majority of work on educational interactive narrative has instead focused primarily on adaptivity [52, 66, 77, 97, 109], interactivity [116, 131], player and knowledge modeling [55, 83, 108], narrative planning and generation [54, 105, 121, 133], emergent narrative [18], player experience [69], and the game creation process [30, 117]. The taxonomy of teaching strategies in VNs presented in this paper serves to broaden the current understanding and impact of educational interactive narratives. Specifically, it explicates design choices for the various teaching strategies that can be employed to deliver educational content-a previously unexplored aspect of educational interactive narrative.

2.1.2 Educational Visual Novels. Although there is no singular accepted definition for VN, the majority of definitions agree that VNs have some form of interactivity and are narrative-focused games with anime/manga influences [48]. VNs have also been employed to teach educational content far more often than traditional interactive narratives, covering a number of topics including secondlanguage acquisition [8, 46, 76], nutrition [48], life management [68], STEM [94, 98], cyber security [50, 57], and cooking [3]. Yet, the majority of these games tend to just be presented as a tool for learning, and are not evaluated for learning outcomes or at best employ extremely limited qualitative or quantitative analysise.g., [50, 53, 76, 78, 99, 119, 127]. However, some recent work has examined and shown the positive effects of educational VNs on self-efficacy and flow [128], as well as improvements to knowledge, learning, and interest when compared to reading non-interactive material [40, 46, 51, 94, 112].

\subsection{Interactive Narrative Design}

Building a taxonomy of teaching strategies for VNs requires understanding of interactive narrative design, and how it relates to the user experience. Specifically, how educational content is delivered and coupled with the story. However, capturing interactive narrative design is still an open problem. Current work focused on capturing and describing game design has produced both computational frameworks and languages (e.g. [85, 113]), but this work rarely focuses on the interaction design and presentation of interactive narrative from the player's perspective.

Interactive narrative is often described in terms of how it is structured using concepts from graph theory [26]. Such descriptions are often used to reference the amount of influence the player is able to have on the progression of the story. E.g., linearly structured narrative indicates no variation in the structure and therefore no influence, whereas branching structures indicate a lot of variation and influence. Several theories and taxonomies have been proposed for interactive narrative structure, with many of them using graph-based representations. Notable examples include Bernstein's hypertext design patterns [22], Lindley's taxonomy [82] building on the work by Eladhari [41], and the Canyon, Deltas and Plains framework of Millard et al. [93]. However, this work has predominantly focused on structural representation, not how the structure was interacted with or traversed mechanically.

In contrast, Carstensdottir et al. [26] used the interaction model of interactive narrative [27] as well as a data of player experience of narrative structure and story progression, to propose a taxonomy of structure and progression mechanics patterns that explicitly frame interaction design patterns in concrete terms. The taxonomy features four different forms of progression: Progression through Discovery, Progression through Choice, Progression through InGame Systems and Progression through Scripted Scenarios [26]. Progression through Discovery refers to mechanics the player must use to locate story content in order to progress the story. For example, in the game Grey Plague [5], the player must find items through the character's room in one scene. Every item provides details about the character's life and even reveals certain choices. Progression through Choice refers to mechanics that allow players to progress in the story by making a direct choice in the story. This usually takes the form of dialogue choices. Progression through InGame Systems refers to mechanics where the player must interact with game systems, such as combat or resource management, in order to progress the story. In Grey Plague, players start the game 
with a series of mini-games where they play as a virus. The story only progresses after the mini-game (task) is finished. This type of progression is through task completion, a subset of Progression through In-Game Systems. Progression through Scripted Scenarios refers to mechanics within scripted events where the player must perform a designated action in order to progress through the story. For example, in Code Romantic [2], players must get all the quiz questions right in order to progress.

In this paper, we build on these patterns and focus our study of the VNs on narrative progression. We choose to focus on progression for two reasons. First, narrative progression is a central component of an interactive narrative experience. Progression occurs when a player uses progression mechanics to traverse the story structure (here understood to be a graph representation of the story events), revealing new content or aspects of the story content as they do so [26]. Second, progression is central to learning, and how the player, as a learner, understands how their actions and choices relate to what they believe they are learning.

\subsection{Diegesis in Interactive Narratives}

Correct and effective communication of information is a central concern for interactive narratives, especially those being used for framing in serious applications such as learning and training games. Often, learning content is communicated across diegetic boundaries, i.e. between the story-world and directly to the player. For example, when characters in a story directly address the player, who is located outside of the story-world.

Diegesis as a concept originated in ancient Greek theatre [21, 96] and can manifests in a variety of different ways depending on the affordances of different media types. While there is considerable work on diegesis in the realms of theatre [21], film [36, 42, 96], and games $[47,61,62,70]$, there is currently "no fully developed and generalizable model of diegesis in digital games." [67]. Kleinman et al. proposed a framework for a player-centered approach to analyzing diegesis focusing on information presentation and player interaction [67]. Within this framework, diegesis is understood as the frame of the story-world. A frame that contains the entirety of the story, and as such confines the story-world within the software window that the interactive narrative and/or the game is presented within. Crossing this diegetic frame crosses the boundary of the story-world (the software window) into the player's world through their apparatus (machine used to run the game) and beyond.

For narrative in educational games, diegesis can impact the presentation of content in relation to how the player and the educational content are diegetically located within and around the game. For example, the manner in which feedback is presented and framed will be affected by whether a player is acknowledged as an outside entity or as a player character [100]. For this study, we focus on diegetic location and diegetic feedback [67].

Diegetic location describes where an action, character, or object are placed in relation to the story-world, or "whether the entity is located inside or outside the fiction of the game" [67]. An object, character, or action is diegetically located if an only if it is located/takes place within the diegetic space of the story world, whereas it is non-diegetically located if it is located/takes place outside the diegetic space of the story world. In educational context, diegetic location can describe where a learning activity occurs. For example, in Gochi-Show! How To Learn Japanese Cooking [3], the characters ask the player to follow along with their recipe in the real world. The cooking activity occurs outside of the game and is therefore non-diegetically located. Alternatively, in After-Party Chemistry [4], the players chooses the player character's answers to questions in class. This activity is diegetically located because the player character answers the questions within the story-world.

Diegetic feedback is defined as "changes that occur within the diegetic space of the story-world and is observable by the characters within it" [67]. One example of diegetic feedback can be seen in KittyClinic [7], where if the player diagnoses a patient incorrectly, the patient will speak to player character in a sad or angry tone. It does not refer to the player as an entity directly. In the same game, the score that the player receives at the end of each in-game day is non-diegetic, as it is feedback directed at the player about their performance, not the player characters.

It is important to note that for educational games, the player can get both non-diegetic feedback relating to their performance, as well as complementary diegetic feedback relating to their player character's performance within the story-world. Receiving feedback both diegetically and non-diegetically allows the player multiple points of reference for their performance and progression through the story. Considering diegetic framing of the delivery and presentation of educational content is therefore highly relevant. The impact of diegetic framing on educational outcomes is, to the authors' knowledge, unknown.

\section{METHODOLOGY}

The methodology employed to create the taxonomy was based on the process of thematic analysis described in [25]. This analytical method was chosen since it is a widely employed method of analysis in qualitative research that focuses on examining themes or patterns of meaning within data (most commonly text) [32], and has previously been employed successfully to analyze interactive narrative games in great detail [25] as well as create game taxonomies, e.g., $[13,130]$.

The thematic analysis process is divided into six phases: 1) $\mathrm{fa}$ miliarization with data, 2) coding, 3) generating initial themes, 4) reviewing themes, 5) defining themes, and 6) reporting. This process was modified to better suit the format of educational VNs, following the changes done with preexisting analyses of interactive narratives in existing literature (e.g., player interaction in narrative games [26]). These modifications include using close reading techniques [23] to identify patterns that inform our taxonomy and find commonalities. We also used the Mechanics, Dynamics, and Aesthetics framework [56] as a way to fully describe the gameplay of educational VNs in a high level manner. Specifically, the researcher performing analysis identified mechanics, dynamics, and aesthetics while playing the educational VNs. This was done to help facilitate the connection of specific gameplay elements identified from playing the educational VNs to teaching techniques. The overall process from coding to concepts to categories is illustrated in Figure 1. The final data set used for analysis consisted of 31 educational VNs drawn from both academia and industry. 


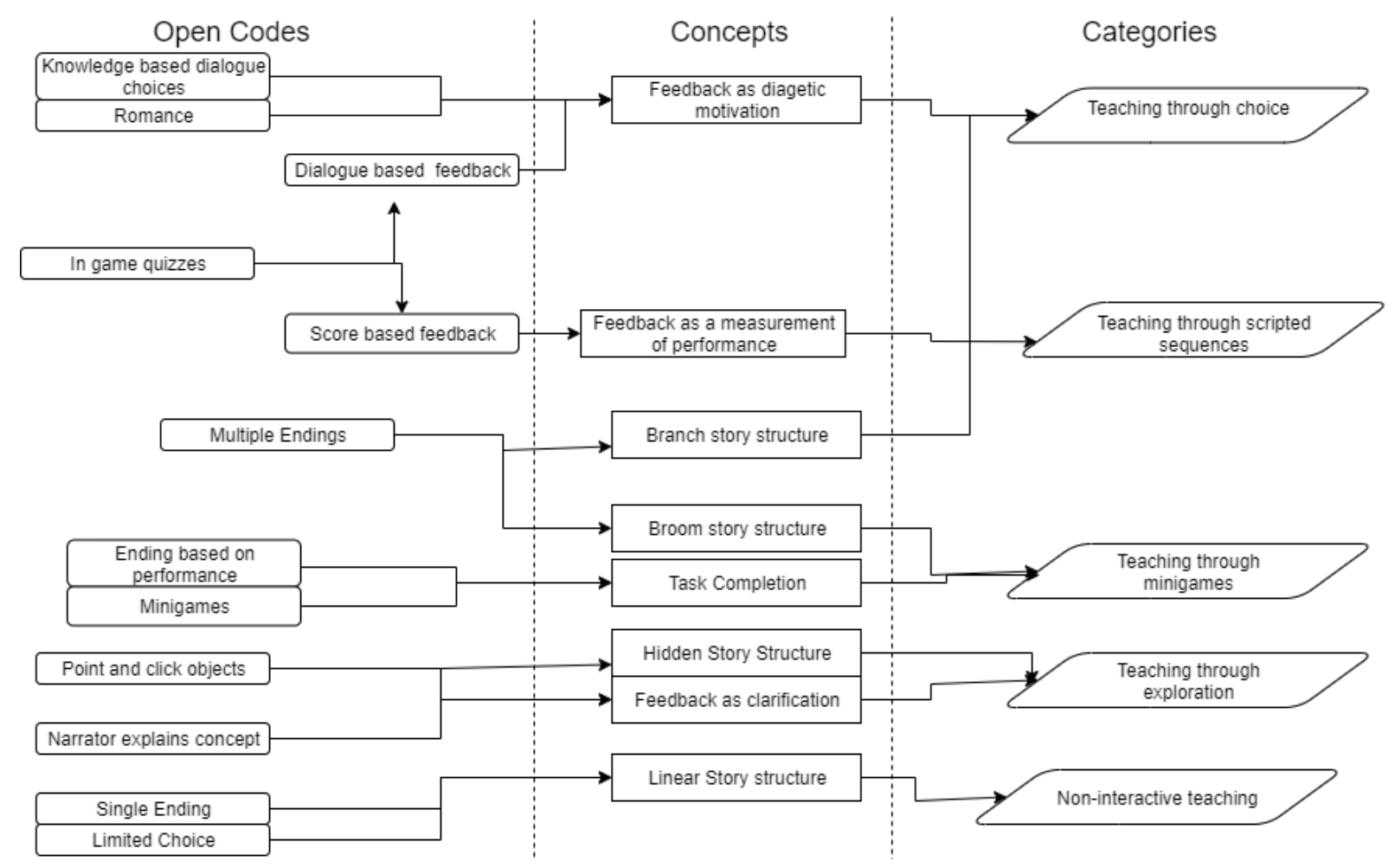

Figure 1: The thematic analysis process for the taxonomy of teaching strategies in Visual Novels with 1) familiarization with the data and coding of narrative progression mechanics; 2) generating initial themes to identify concepts using the structure of the story, player interaction, and how diegetic feedback is presented; and 3) reviewing themes to determine taxonomy categories and report how educational content is delivered through teaching strategies in VNs.

\subsection{Search Strategy and Observations}

The VNs described in this survey were found through popular commercial video game digital distribution services (itch.io, Steam, and Google Play), as well as through an extensive search of academic articles in Google Scholar and from proceedings of FDG, DiGRA, ICIDS, and CHI Play - resulting in twenty-three papers on educational VN games. Notably, the search term employed on the digital distribution services and Google Scholar was "educational visual novel". This term was chosen because it filtered out games that did not meet both conditions of being educational and a visual novel. I.e., many educational games are not visual novels, and many visual novels are not educational. This also allowed games to be identified as educational VNs through tags provided by the game distribution platforms or by self-identification in academic articles. Self-identification was employed as the primary approach for selecting games since, as noted earlier, there is not a standard definition for Visual Novel. This avoided bringing in researcher biases when defining a game as Visual Novel, and ultimately made identifying games of this genre clearer and easier.

Overall, thirty-one games were identified and collected for analysis, with eighteen coming from independent studios/developers that were readily available for play by the general public. The remaining thirteen games came from the twenty-three academic papers and were largely not obtainable for play, but did discuss the VNs and their designs in detail. For analysis, all publicly available games were played on a computer with Microsoft Windows, while the remaining unavailable academic games were analyzed from their descriptions in research papers.

Games were first played by a single researcher acting as a "naive reader" for up to an hour without analysis-this can create authentic experience which produces valuable insights $[11,23]$. We employed the single researcher approach to avoid multiple interpretations of the game and for consistency. However, this will likely not fully reflect all possible play styles and could introduce single researcher related biases. To reduce the potential impact of these limitations, weekly reviews were conducted between three researchers to discuss the classifications and codes generated by single the researcher playing the games. Additionally, prior research, i.e., [26], has utilized the same single researcher approach in the analysis of interactive narrative games.

For the analysis, a single researcher played the games and paused to take notes. These insights were recorded as short descriptions of gameplay and learning experience. The researcher then switched to an observational approach where the $\mathrm{VN}$ was treated as a series of mechanical interactions. This included recording platform, features, educational topic, teaching methods, and notable design elements. This data focused on the mechanics or rules of the VN [56]. For games that were not accessible, the researcher relied on videos and 


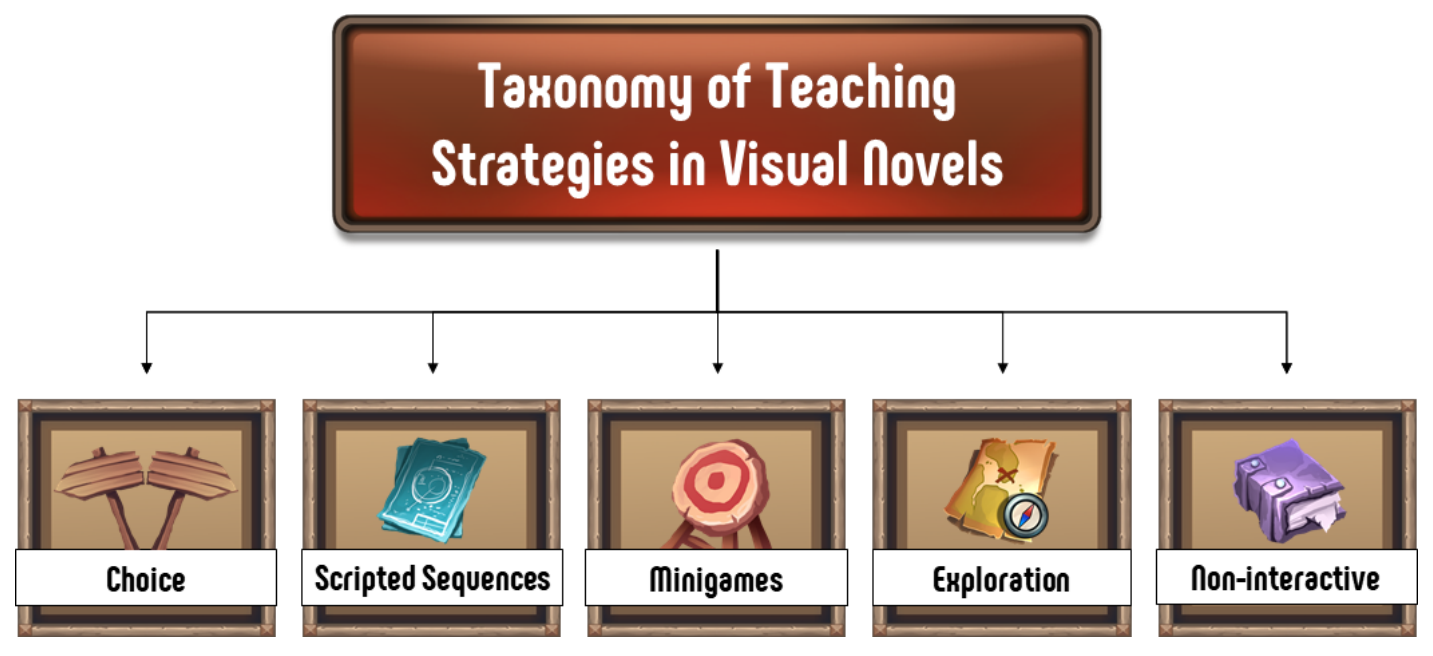

Figure 2: The Taxonomy of Teaching Strategies in Visual Novels.

descriptions of the $\mathrm{VN}$ from its corresponding paper(s) to generate insights and descriptions of mechanical interactions. This stage is synonymous with familiarization with data, and coding [25].

\subsection{Generating and Reviewing Concepts}

In this phase, a researcher used the collected data and applied two descriptive Interactive Narrative design frameworks [26, 67] to code the designs of all the games in the data set. Gameplay was reexamined for the type, timing, and delivery of feedback. Narrative progression and story structure were also reviewed. This phase helped codify the designs, to create an understanding of specific dynamics [56], and how the mechanics of the game interact with the player and learning.

\subsection{Defining Themes and Reporting}

In this phase, five key teaching strategies for VNs were identified, informed by educational literature such as [64, 81, 125]. Specifically, strategies were identified by examining Interactive Narrative concepts/codes and how they worked together with concepts from existing educational literature to support learning-akin to the process employed in [90]. These strategies were then examined for aesthetics [56], how the the dynamics created motivation for learning (agency) [19], and how the content delivery enforces player engagement with educational material (cognitive engagement) [16]. The resulting taxonomy with five key categories of teaching strategies is shown in Figure 2. The categorization of each educational VN by teaching strategy is also shown in Figure 3.

\section{TAXONOMY OF TEACHING STRATEGIES IN EDUCATIONAL VISUAL NOVELS}

\subsection{Teaching Through Choice}

In this strategy, the focus on learning and story progression is through the selection of explicit choices for the player's character. In this way, concepts are delivered through the player experiencing the effects of their choices. This dimension draws from notions of choice-based learning [45, 63] and self-determination theory [37] in learning science and serious games literature, which have shown the substantial impact such approaches can have on autonomy, engagement, and learning $[44,114]$. For this strategy, feedback was observed to be generally diegetic, aiming to provide diegetic consequences that could represent real life consequences. It is important to note that for a game to fall under this category, the feedback given by the characters or story has to be meaningful. Players can encounter and receive immediate and non-meaningful response, and as such "the existence of local agency does not guarantee the presence of emotional agency." [72].

Examples of VNs from our data set that fall under this category include Time Mage [128] (see Figure 4), a story where the player character has the power of time travel-which allows them to go back in time to save a family member from a heart attack. As a result, the game allows the player character to virtually experience the learning content (i.e., improved patient engagement) through their choices. The consequences of choices to the story are not always immediate since the game does not explicitly say that they made a mistake. Instead, these mistakes lead to the eventual death of a loved one, creating a sense of global agency [86]. This strategy takes a constructive approach to learning, encouraging learners to actively process and organize information by making new internal cognitive connections [120]. It is also frequently used to make emotional arguments in games such as Katawa Shoujo [28].

\subsection{Teaching Through Mini-games}

In this educational VN teaching strategy, players are taught concepts through playing mini-games-which has had a long history of use in serious games $[49,115]$ and has been shown to be an effective educational tool for such games [58, 60]. As such, these mini-games can employ standard educational game design concepts such as assessment and learning mechanics [73, 103]. With respect to VNs, the progression of the story is tied to the player's performance in an underlying system [26], in this case, mini-games. As a result, these mini-games ultimately have players either demonstrate/assess their knowledge [103] or practice an activity to reinforce learning [106] in order to progress through the story. They also often use a form 


\begin{tabular}{|c|c|c|c|c|c|}
\hline Adventures in Research & $\mathrm{X}$ & & & & \\
\hline After-Party Chemistry & & & & & $\mathrm{X}$ \\
\hline Amigo & $\mathrm{X}$ & & $\mathrm{X}$ & & \\
\hline Artificial Tomodachi & & & $\mathrm{X}$ & & \\
\hline Benthic Love & & $\mathrm{X}$ & & & \\
\hline Burn Your Fat With Me! & & & & $\mathrm{X}$ & $\mathrm{X}$ \\
\hline Clinical Encounters: Alice & & & & & $\mathrm{X}$ \\
\hline Code Romantic & & & & & $\mathrm{X}$ \\
\hline Conversation Construction & & & & & $\mathrm{X}$ \\
\hline Conversation Gambits & & & & & $\mathrm{X}$ \\
\hline Count With Me! & & & $\mathrm{X}$ & & \\
\hline $\begin{array}{l}\text { Cyber Security Awareness } \\
\text { Game }\end{array}$ & & & & & $\mathrm{X}$ \\
\hline GLOBALL Manager & & $\mathrm{X}$ & $\mathrm{X}$ & & \\
\hline Gochi-Show! For Girls & & & & $\mathrm{X}$ & $\mathrm{X}$ \\
\hline $\begin{array}{l}\text { Gochi-Show! How To Learn } \\
\text { Japanese Cooking }\end{array}$ & & & & $\mathrm{X}$ & $\mathrm{X}$ \\
\hline GoML & $\mathrm{X}$ & & & & \\
\hline Grey Plague & $\mathrm{X}$ & $\mathrm{X}$ & & & $\mathrm{X}$ \\
\hline Heirdom & & $\mathrm{X}$ & $\mathrm{X}$ & & \\
\hline InSiKids & & & $\mathrm{X}$ & & \\
\hline Katawa Shoujo & $\mathrm{X}$ & & & & \\
\hline KittyClinic & $\mathrm{X}$ & $\mathrm{X}$ & & & \\
\hline $\begin{array}{l}\text { Learn Japanese To Survive! } \\
\text { Kanji Combat }\end{array}$ & & & $\mathrm{X}$ & & $\mathrm{X}$ \\
\hline Must Love Jaws & & & & $\mathrm{X}$ & \\
\hline Osiris & & $\mathrm{X}$ & $\mathrm{X}$ & & \\
\hline Policy World & & $\mathrm{x}$ & $\mathbf{X}$ & & \\
\hline Puppy Chef Academy & & & & & $\mathrm{X}$ \\
\hline Stalker Behavior & $\mathrm{X}$ & & & & \\
\hline Surfacing Intuitions & $\mathrm{X}$ & & & & \\
\hline Tales Of Ancient Nights & & & & $\mathrm{X}$ & \\
\hline The Expression Amrilato & $\mathrm{X}$ & & $\mathrm{X}$ & & \\
\hline The Time Mage & $\mathrm{X}$ & & & & \\
\hline
\end{tabular}

Figure 3: Categorization of educational Visual Novels by teaching strategy.

of non-diegetic feedback [67] to clearly convey messages relevant
A group of nurses show up around the corner, one of them A group of nurses show up around the corner, one of them
glancing at you as they are approaching the emergency room.
She is wearing a badde. You can't quite read it, but she seems
to be the head nurse. the head nurse.

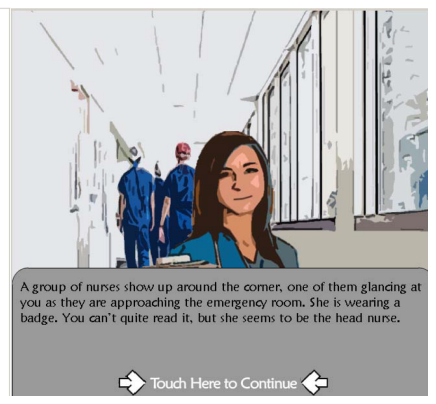

Figure 4: An example of Teaching Through Choice in The Time Mage [128]. The player makes choices to save a loved one, and with the checkpoint system, players can learn from their mistakes.

to the player and learning content, but not the story. Ideally, mastering mini-games with this teaching strategy requires mastering the educational material. For example, Learn Japanese To Survive! Kanji Combat [8] is an educational VN about learning Kanji (see Figure 5). In it the player must fight all of the Kanji enemies during mini-games by correctly answering what each character is in order to progress through the story, allowing the player to practice reading Kanji.

\subsection{Teaching Through Scripted Sequences}

Scripted sequences was the most frequently employed teaching strategy in our data set, with the player's progression through the story being reliant upon scripted sequences (i.e., scenarios) [26]. Unlike in teaching through mini-games, scripted sequences require the player to perform the designer's exact intended actions before allowing them to progress, and typically utilize pedagogical theory focused on demonstrating real problems from the knowledge domain as well as guiding/applying a learner's knowledge-i.e, guided experiential learning [31]. This often takes the form of interactive cut scenes or in-game quizzes. For educational VNs, this attempts to ensure that players experience or interact with all the desired educational content.

Overall, scripted sequences are generally used as a transmission model of teaching [75], where the student is first given instruction and then is accessed through testing. This is seen in many of the educational VNs from our data set, such as Code Romantic [2], where the player character first reads an explanation given in the academy and then is asked to debug related code based on that information (see Figure 6 Top).

Scripted sequences can also be used as a form of structure inquiry [132], where the student investigates a (in-game) teacher-presented question through a prescribed procedure. An example of a game that falls under this category is The Grey Plague [5], where the player's character is a university student with superhuman immunity investigating a mysterious disease. In the opening sequences, the player must finish an interactive cut-scene as the character talks to their mother about diseases. For example, when the mother explains to the main character how the viruses can travel to the lung, the player's character takes the role as a virus moving through 


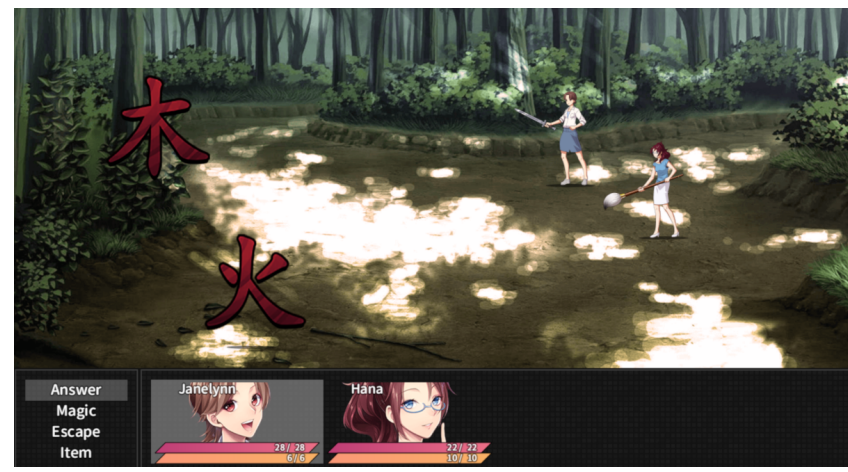

Figure 5: An example of Teaching Through Mini-games in Learn Japanese To Survive! Kanji Combat. The player practices reading Kanji by select the corresponding English word in a list of attacks.

the body (see Figure 6 Bottom). The scenario in this case explains concepts through dialogue.

\subsection{Teaching Through Exploration}

In this strategy, the player is taught concepts through exploration of the game's world. This type of teaching relies on self exploration, and oftentimes employs a hidden story structure where players have to discover story content in order to progress [26]. Players are also typically given additional information, including educational content, about what they discover through narration. As a result, exploration, in this case, acts as both educational delivery as well as progression through discovery.

One notable game which employs this strategy is Osiris [9]. In the game, the player's character is a student who is whisked into ancient Egypt, where they meet characters based on mythology, like Osiris and Isis, and can learn about Egypt's mythology through interacting with them (see Figure 7). The story of the game progresses through finding and clicking on hidden items. When the player finds new objects, their character provides narration that connects it to the real world. In addition, finding all the objects such as finding all of Osiris's body parts unlocks new parts of the story.

Teaching through exploration in this context is similar to guided inquiry learning [71], where the $\mathrm{VN}$ establishes a set of questions and procedures that students can choose to follow [132] (in this case the implemented action set [67]). It also leverages the learning by exploration dimension of Lim's Six Learnings framework [81] and learner control game attribute from the conceptual framework for serious games by Yusoff et al. [129] to guide gameplay to achieve desired learning outcomes [76]. Notably, the games in this categorization of teaching strategies for educational VNs showed that exploration is almost always paired with another strategy. One likely explanation is that exploration alone does not provide any direct application of knowledge, a key part of inquiry [132]. Therefore, these games have to rely on another strategy to have players apply knowledge and verify learning outcomes.

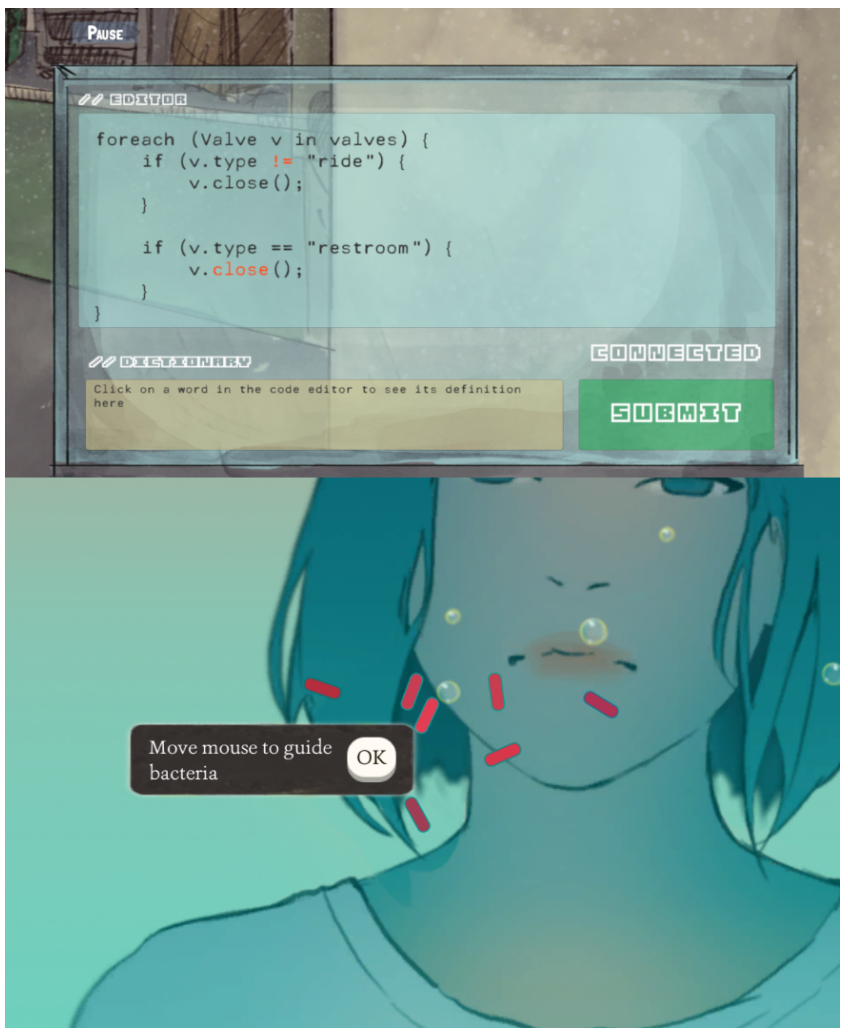

Figure 6: Examples of teaching through scripted sequences. Top) Code Romantic: the player cannot progress until they pick all the correct syntax for the current hack slate (program). Bottom) The Grey Plague: the player takes the role of bacteria to show how viruses and germs can travel.

\subsection{Non-interactive Teaching}

In this teaching strategy, educational VNs rely solely on narration and character dialogue to convey educational content and teach players. Unlike other strategies, this strategy teaches passively with learners receiving information without doing any activities to learn new concepts or reinforce existing ones. As a result, player knowledge is irrelevant to the story progression, and the selection of choices does not rely on the concepts being taught. According to the ICAP model, this teaching strategy is less effective than more active strategies [29]. Fortunately, this was the least used strategy among all games from the data set.

\section{DISCUSSION}

In building the taxonomy, five types of teaching strategies were identified in existing educational VNs-each with their own particular implications for design. In this section, we discuss the design implications of these strategies in relation to their educational effectiveness. In addition, we discuss two notable features of VNs as a genre, Romance and Choices, and how they were utilized in educational VNs. 


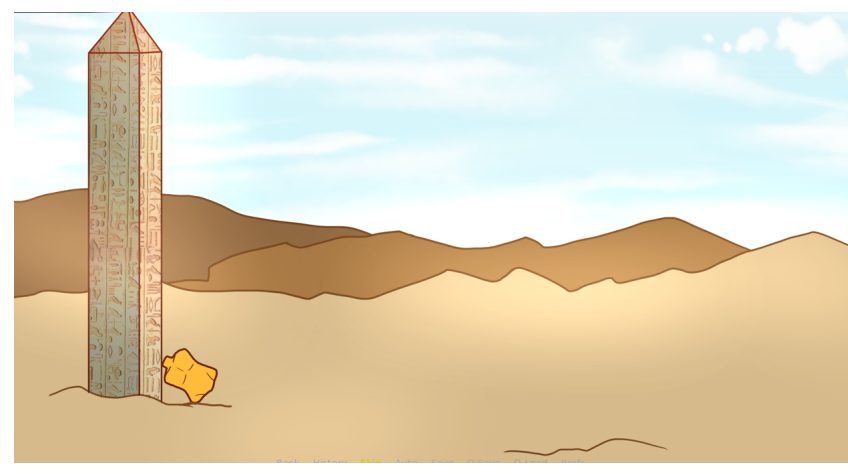

Figure 7: An example of teaching through exploration in Osiris. The player learns more about Egyptian mythology by interacting with characters and finding hidden items, like Osiris' dead body parts.

\subsection{Design Implications}

5.1.1 Scripted Sequences and Non-interactive Teaching in Practice. Games employing the Scripted Sequences and Non-interactive Teaching strategies also typically used non-interactive materials such as videos to deliver educational content-pairing it with selfreport testing for assessment of learning. However, if the Scripted Sequences strategy is not supporting knowledge acquisition or a particular learning outcome then it might be perceived as trivial or non-interactive by the player-as it effectively removes learning as a requirement of progression. That is not to say, however, that all Scripted Sequence or Non-interactive Teaching strategies fail to impart the impression of agency within the play experience, and thus fail to motivate players to perform actions or learn [72]. For instance, agency can emerge in a variety of contexts such as being motivated enough to press buttons to make a character crawl faster through a tunnel despite the buttons not having any effect. For educational games, this is known as immersion, described as pleasurable surrender to an imagined space, and is linked to effective learning environments within the ARCS model [35]. Therefore, for Scripted Sequences and Non-interactive Teaching to be effective as teaching strategies for educational VNs, they must focus heavily on making the narrative immersive and strongly incorporating the educational content that narrative.

5.1.2 Dynamic Difficulty Adjustment and Mini-games. Mini-games are not only used as progression through task completion [26] but can also serve as a means of dynamic difficulty adjustment (DDA) [38]. As an illustrative example, Heirdom [98] features a role-based system where players are given quests (i.e., mini-games) based on their choices and previous performance. Players that perform well are given harder quests while players performing poorly are given easier ones. This system also implements Player oriented DDA (PDDA) where players are given additional control over the difficulty adjustment through choices [15]. After the player completes each quest, choices that determine future quest difficulty are presented as part of a dialogue between the player character and the quest giver. This frequency of PDDA at regular intervals has been shown to be more effective than constant or one-time PDDA [15]. Notably, Interactive Narratives and more specifically VNs typically give players choices at regular intervals. These periodical events naturally map to periodic PDDA, and therefore suggest that VNs which employ mini-games have underexplored potential to support PDDA. Furthermore, PDDA in educational VNs address the confidence factor of the ARCS model, i.e. players are motivated to learn when challenges are neither too difficult or easy [35]. This can create a state of flow in the player which promotes better learning outcomes [35]. Recent work (i.e., in a study of Time Mage [128]) further indicates that the confidence factor of ARCS is important to educational VNs, finding a positive correlation between flow score and desired learning achievement.

PDDA in educational VNs can also be viewed as a form of dialogue between the instructor (the game) and the student (the player), which is important for educational efficacy. Specifically, the conversational framework for education [75] states that for effective learning to occur, the continuous interactive dialogue between teachers and students is essential. Students in this case indirectly communicate their understanding through mini-games, and the instructors (the game) provide feedback. This feedback can take form of diegetic feedback in response to the player's performance or in a more direct manner in the form of non-diegetic feedback. Notably, this conversation continues when the player makes dialogue choices in relation to difficulty [98]. Overall, this can create a useful loop for educational delivery, depending on how well the $\mathrm{VN}$ interprets and presents player choice and action.

5.1.3 Choices and Checkpoints. Teaching through Choices teaches players through the diegetic consequences of their action. This is based on the player's user experience loop [67]: 1) a player first considers their possibilities; 2) then carries out their action if possible; and 3) finally, the player observes the consequences of their actions and the loop repeats. Teaching through Choices thus relies on the player's inference and reflection on their actions, and the resulting consequences thereof. However, consequences can have both immediate (local) and delayed (global) consequences in terms of the story, which might not be obvious until much later. For example, in the Time Mage, the main character's loved one may not immediately die after one bad choice but instead may die after a series of bad choices [128].

For learning, such unclear and delayed consequences might not be desirable, and more immediate feedback from consequence or experimentation preferred [79]. Notably, in the Time Mage, players can use a checkpoint to go back to a dialogue choice and try something different[128]. This allows the player to more explicitly consider their choices and mistakes, and gives them a chance to form a hypothesis about their future choices. Such an approach utilizing checkpoints in educational VNs encourages exploration, allowing the player to move between checkpoints on each playthrough and thus making the process iterative. In this way, checkpoints fulfill the three conditions of the process for learning in a Conversational Framework For Individual Learning [75]. I.e., in Time Mage, the three conditions are represented as learner conception through practice (making choices based on previous play through), learner conception through reflection (the theories the learner forms about self-efficacy in healthcare), and a teacher-designed task environment (the narrative which changes on player actions) [75]. As a result, the creators of Time Mage found that when players were 
engaged in the story, this strategy improved player's performance relative to participants that read a brochure [128].

5.1.4 Exploring Fictional Worlds. Games that teach through Exploration use Progression through Discovery [67] as a method of examining the fictional world in relation to educational concepts, as well as pedagogical approaches such as guided discovery [74] and guided inquiry learning [71] to transfer educational knowledge. For example, Osiris [9] allows players to form connections between the diegetic world of the game and Egyptian Mythology. The exploration takes the form of exploring dialogue to gain information about characters, and through point and click based tasks such as search and puzzle solving. This approach encourages players to examine the fictional world in more detail, and benefits from having fictional worlds that connects to the educational material. This supports the Attention factor of the ARCS model [35], as it employs strategies that maintain curiosity and interest. In this case, in a fictional world that resembles Egyptian Mythology.

This strategy can also work well for games that try to teach a process or methodology. For example, in the game KittyClinic [7] the learner plays as a nurse who has to holistically diagnose cats that live human-like lives. Just as Osiris strongly mimics its Egyptian mythology, the cats in this game are clearly symbolic of human patients. The player is told to practice using a holistic approach that involves searching for patient files, finding medical articles, and connecting it with the patient's response. This could be considered Teaching through Mini-games, but the game has strong mismatch between its implemented actions set and its presented action set [67]. In other words, the affordances of the game are not always made clear to the player. Instead, it relies on players attempting different actions and discovering important processes to learn [74] However, while exploration can encourage players to examine the fictional world more closely and make non-diegetic connections, it also has the possibility of the player never discovering all the educational content.

\subsection{Notable Design Elements}

Although an agreement of a definitive definition of the term "Visual Novel" has not been reached within the interactive narrative community, there are two notable elements that are commonly associated with the genre: romance and choices.

5.2.1 Romance. Romance is a popular subject matter for Visual Novels. According to VNStat, a site visualizing data from a communitymaintained Visual Novel Database, over two-thousand VNs are tagged with the element/genre ${ }^{1}$. Notably, the four tags that come before romance in popularity include ADV, Male Protagonist, Protagonist with a Face, and Multiple Endings. These tags were either too vague or non-genres. Despite the popularity and prevalence of the subject within the VN genre, only four of the games surveyed $[1,2,4,10]$ use romance as part of their educational delivery.

We argue that romance is under utilized in educational VNs, and that it has the potential to greatly improve player motivation and immersion. Given its popularity with current VN players, it could also be leveraged to spark interest and engagement in various subject matters. For instance, romance can facilitate a character

\footnotetext{
${ }^{1}$ https://vnstat.net/tag/96
}

focused approach, using player attachment to characters to motivate them to invest in the game's goal [95] and giving the player agency to choose the manner in which they engage. Not only is this beneficial for maintaining a player's attention, motivation is also a is prerequisite for learning [125]. As an example, in After-Party Chemistry [4], there is a direct relationship between knowledge and character relationships. The main character's relationship deepens as the teacher is attracted to the character's determination, which is expressed through the player's performance on quizzes. This direct relationship can ultimately motivate the player to learn educational material in order to help progress the romance.

5.2.2 Choices. Choices play an integral role in VNs and can further enhance different educational delivery strategies. VNs are commonly known for featuring progression through choice selection [26], and while some VNs such as Heirdom [98] and Learn Japanese To Survive! Kanji Combat [8] use other forms of teaching strategies such as mini-games, narrative choices are still a key element in these VNs. In general, choices are a direct form of control over the story, however Kway and Mitchell also suggest three other categories of choices that provide agency: flavour choices, unchoices, and false choices [72]. We observed that these most of these choice types were utilized in combination with the teaching strategies of the VNs in our data set, albeit not as frequently.

Flavour choices are not meaningful to the system or story but instead allow players to express themselves [72]. In the data set, Flavour choices were used in combination with games using Teaching Through Exploration and Non-Interactive Teaching strategies. For example, in KittyClinic [7], the player is given different options to respond to the owner's use of cat puns. Although these choices have no effect on the story, they do allow the players to define their character's role in the story.

Unchoices are choices with only one option [72]. In the data set, Unchoices were used in combination with Teaching Through Scripted Sequences. Progression through Scripted Scenarios [26] have players follow the designers predetermined actions exactly. In Teaching Through Scripted Sequences players are asked to follow specific set of instructions, this can be interpreted as both Progression through Scripted Scenario as well as an unchoice. For example, in Code Romantic [2], players are asked to complete code on the hack slates to complete a test for their character, but are only presented with one choice. However, players may still feel responsible for their character's success in the game, thus creating an illusion that their choices matters to the narrative. These types of choices can enforce emotional agency [72] if utilized properly.

False choices are choices where all the options lead to the same outcome [72]. In terms of structure, this can be considered to be similar to a Foldback structure type [26]. In the data set, False choices were not used. Kway and Mitchell argue that these types of choices can create a certain level of agency through authorial intent [72]. Inclusion of these types of choices could therefore, in certain cases, be used to enhance educational delivery.

\section{LIMITATIONS AND FUTURE WORK}

The methodology used to produce the taxonomy has certain limitations that influenced the taxonomy. One such limitation was that there was only one researcher playing the games. This can 
potentially introduce personal biases to the observations made. For instance, the playthroughs done by the researcher will likely not fully reflect all possible play styles. Similarly, the different elements observed in the educational VNs may not have been classified in the same way by other researchers. We worked to reduce the potential impact of some of these limitations by having weekly reviews between all authors to discuss the classifications and codes generated by the researcher playing the games. Self-identification is also a limiting factor, particularly for games on itch.io where creators set their own tags. This can result in games with significantly different mechanics being categorized as the same genre. Finally, visual novels as a genre does not have a clear consensus of a definition. This limits the ability to filter games and limits the possible search criteria. Future work will seek to create a more unified definition of VNs to better identify such games and their uses for education. Finally, due to time and size constraints, the effectiveness of each teaching strategy is not evaluated. Instead, this taxonomy provides groundwork for future analyses and explorations, including discussions with expert designers.

\section{CONCLUSION}

VNs, as a sub-genre of interactive narratives, are widely used for educational purposes due to their popularity and accessibility. For educational VNs, the narrative helps frame educational content and its delivery, while also providing a narrative engagement and motivation for the player. Educational VNs have also proven effective as a learning tool over traditional non-interactive materials, but unfortunately remain understudied in terms of their design and effectiveness at achieving desired learning outcomes.

In this paper we present a taxonomy of teaching strategies for educational VNs, focusing on the different strategies and designs employed by exiting educational VNs for the delivery of educational content. Through thematic analysis of a set of 31 educational visual novels, five teaching strategies were identified: teaching through Choice, Scripted Sequences, Mini-games, Exploration, and NonInteractive teaching. We discussed examples of how each strategy can be defined and its main design features. These strategies allow for closer examination and categorization of educational VN designs and the relationship between educational content delivery and story progression, which have potential broader implications for the use of interactive narrative in education. Notably, these strategies are not mutually exclusive and educational VNs in the data set were sometimes found to employ more than one strategy. We discussed implications for design as it relates to theoretical learning effectiveness, such as the educational implications of how Scripted Sequences and Non-Interactive Teaching were utilized in practice. Finally we discussed how two notable and popular elements of the VN genre, romance (as a topic and collection of relationship mechanics) and choices, were utilized in relation to education. Surprisingly, we found that romance, while immensely popular by players of the genre, was not prevalent in educational VNs.

Overall, this paper provides designers and researchers with strategies and suggestions for identifying more potentially effective ways to deliver educational content, as well as to evaluate how narrative is used to complement educational content delivery. It is our hope that classifying the different designs of VNs employed for education will ultimately allow us to improve the design, presentation, and interaction with educational subject matter in interactive narrative games.

\section{REFERENCES}

[1] 2014. Benthic Love. Game [Itch.io]. https://joffeorama.itch.io/benthic-love

[2] 2016. Code Romantic. Game [Itch.io]. https://prettysmart.itch.io/code-romantic

[3] 2016. Gochi-Show! How To Learn Japanese Cooking. Game [Steam].

[4] 2017. After-Party Chemistry. Game [Itch.io]. https://xxmissarichanxx.itch.io/ after-party-chemistry

[5] 2017. Grey Plague. Game [Itch.io]. https://zephyo.itch.io/grey-plague

[6] 2018. Artificial Tomodachi. Game [Itch.io]. https://anima-game.itch.io/artificialtomodachi

[7] 2018. KittyClinic. Game [Itch.io]. https://cnnmon.itch.io/kittyclinic

[8] 2018. Learn Fapanese To Survive! Kanji Combat. Game [Steam].

[9] 2018. Osiris. Game [Itch.io]. https://yuenriartworks.itch.io/osiris

[10] 2019. The Expression Amrilato. Game [Steam].

[11] Espen Aarseth. 2007. Playing Research: Methodological approaches to game analysis. Artnodes 0, 7 (Jan 2007). https://doi.org/10.7238/a.v0i7.763

[12] Espen Aarseth, Solveig Marie Smedstad, and Lise Sunnanå. 2003. A multidimensional typology of games.. In DiGRA Conference.

[13] Leigh Achterbosch, Charlynn Miller, and Peter Vamplew. 2017. A taxonomy of griefer type by motivation in massively multiplayer online role-playing games. Behaviour \& Information Technology 36, 8 (2017), 846-860.

[14] Sultan A Alharthi, Olaa Alsaedi, Zachary O Toups, Joshua Tanenbaum, and Jessica Hammer. 2018. Playing to wait: A taxonomy of idle games. In Proceedings of the 2018 CHI Conference on Human Factors in Computing Systems. 1-15.

[15] Dennis Ang and Alex Mitchell. 2019. Representation and Frequency of Player Choice in Player-Oriented Dynamic Difficulty Adjustment Systems. Proceedings of the Annual Symposium on Computer-Human Interaction in Play (2019). https: //doi.org/10.1145/3311350.3347165

[16] Leonard A. Annetta, James Minogue, Shawn Y. Holmes, and Meng-Tzu Cheng. 2009. Investigating the impact of video games on high school students' engagement and learning about genetics. Computers \& Education 53, 1 (2009), 74-85. https://doi.org/10.1016/j.compedu.2008.12.020

[17] Alissa N Antle and Alyssa F Wise. 2013. Getting down to details: Using theories of cognition and learning to inform tangible user interface design. Interacting with Computers 25, 1 (2013), 1-20.

[18] Ruth S Aylett, Sandy Louchart, Joao Dias, Ana Paiva, and Marco Vala. 2005. FearNot!-an experiment in emergent narrative. In International Workshop on Intelligent Virtual Agents. Springer, 305-316.

[19] Ryan S.j.d. Baker, Sidney K. Dmello, Ma.mercedes T. Rodrigo, and Arthur C. Graesser. 2010. Better to be frustrated than bored: The incidence, persistence, and impact of learners' cognitive-affective states during interactions with three different computer-based learning environments. International fournal of HumanComputer Studies 68, 4 (2010), 223-241. https://doi.org/10.1016/j.ijhcs.2009.12. 003

[20] Wendy L Bedwell, Davin Pavlas, Kyle Heyne, Elizabeth H Lazzara, and Eduardo Salas. 2012. Toward a taxonomy linking game attributes to learning: An empirical study. Simulation \& Gaming 43, 6 (2012), 729-760.

[21] Karol Berger. 1994. Diegesis and Mimesis: The Poetic Modes and the Matter of Artistic Presentation. The fournal of Musicology 12, 4 (1994), 407-433.

[22] Mark Bernstein. 1998. Patterns of Hypertext. In Proceedings of the Ninth ACM Conference on Hypertext and Hypermedia: Links, Objects, Time and Space (HYPERTEXT '98). ACM, New York, NY, USA, 21-29. https://doi.org/10.1145/276627. 276630

[23] Jim Bizzocchi and Theresa Tanenbaum. 2011. Well Read: Applying Close Reading Techniques to Gameplay Experiences. $262-290$.

[24] Elizabeth A Boyle, Thomas Hainey, Thomas M Connolly, Grant Gray, Jeffrey Earp, Michela Ott, Theodore Lim, Manuel Ninaus, Claudia Ribeiro, and João Pereira. 2016. An update to the systematic literature review of empirical evidence of the impacts and outcomes of computer games and serious games. Computers \& Education 94 (2016), 178-192.

[25] Virginia Braun and Victoria Clarke. 2006. Using thematic analysis in psychology. Qualitative Research in Psychology 3, 2 (2006), 77-101. https://doi.org/10.1191/1478088706qp063oa arXiv:https://www.tandfonline.com/doi/pdf/10.1191/1478088706qp063oa

[26] Elin Carstensdottir, Erica Kleinman, and Magy Seif El-Nasr. 2019. Player interaction in narrative games. Proceedings of the 14th International Conference on the Foundations of Digital Games - FDG 19 (2019). https://doi.org/10.1145/ 3337722.3337730

[27] Elin Carstensdottir, Erica Kleinman, and Magy Seif El-Nasr. 2017. Towards an Interaction Model for Interactive Narratives. In Interactive Storytelling. ICIDS 2017. Lecture Notes in Computer Science, Vol. 10690 LNCS. https://doi.org/10. 
1007/978-3-319-71027-3 24

[28] A Champlin. 2014. Playing with Feelings: Porn, Emotion, and Disability in Katawa Shoujo. Well Played 3, 2 (2014), 63-81.

[29] Michelene T. H. Chi and Ruth Wylie. 2014. The ICAP Framework: Linking Cognitive Engagement to Active Learning Outcomes. Educational Psychologist 49, 4 (Feb 2014), 219-243. https://doi.org/10.1080/00461520.2014.965823

[30] Dimitrios Christopoulos, Pavlos Mavridis, Anthousis Andreadis, and John N Karigiannis. 2011. Using Virtual Environments to Tell the Story:" The Battle of Thermopylae". In 2011 Third International Conference on Games and Virtual Worlds for Serious Applications. IEEE, 84-91.

[31] Richard E Clark. 2005. Guided experiential learning: Training design and evaluation. Center for Cognitive Technology, Rossier School of Education, University of Southern California (2005).

[32] Victoria Clarke and Virginia Braun. 2013. Teaching thematic analysis: Overcoming challenges and developing strategies for effective learning. The psychologist 26, 2 (2013).

[33] Marjorie Ann M Cuerdo and Edward F Melcer. 2020. "I'll Be Back": A Taxonomy of Death and Rebirth in Platformer Video Games. In Proceedings of the $2020 \mathrm{CHI}$ Conference Extended Abstracts on Human Factors in Computing Systems.

[34] Polina Danilicheva, Stanislav Klimenko, Yury Baturin, and Alexander Serebrov. 2009. Education in virtual worlds: Virtual storytelling. In 2009 International Conference on CyberWorlds. IEEE, 333-338.

[35] Roman Danylak. [n.d.]. Gestural Motivation, Learning and Evaluation using Interactive Game Design. Advances in Game-Based Learning Handbook of Research on Improving Learning and Motivation through Educational Games ([n. d.]), 512-528. https://doi.org/10.4018/978-1-60960-495-0.ch024

[36] Stephen Boyd Davis. 2002. Interacting with pictures: film, narrative and interaction. Digital creativity 13, 2 (2002), 71-84.

[37] Edward L Deci and Richard M Ryan. 2012. Self-determination theory. (2012).

[38] Alena Denisova and Paul Cairns. 2015. Adaptation in digital games: the effect of challenge adjustment on player performance and experience. In Proceedings of the 2015 Annual Symposium on Computer-Human Interaction in Play. 97-101.

[39] Michele D Dickey. 2006. Game design narrative for learning: Appropriating adventure game design narrative devices and techniques for the design of interactive learning environments. Educational Technology Research and Development 54, 3 (2006), 245-263.

[40] Matthew W. Easterday and I. Yelee Jo. 2014. Replay Penalties in Cognitive Games. Intelligent Tutoring Systems Lecture Notes in Computer Science (2014), 388-397. https://doi.org/10.1007/978-3-319-07221-0_48

[41] Mirjam Eladhari. 2002. Objektorienterat berättande i berättelsedrivna datorspel. Object Oriented Story Construction in Story Driven Computer Games”). Yayınlanmamış Yüksek Lisans Tezi (2002).

[42] Thomas Elsaesser and Malte Hagener. 2015. Film theory: An introduction through the senses. Routledge.

[43] Christian Elverdam and Espen Aarseth. 2007. Game classification and game design: Construction through critical analysis. Games and Culture 2, 1 (2007) $3-22$.

[44] Deniz Eseryel, Victor Law, Dirk Ifenthaler, Xun Ge, and Raymond Miller. 2014 An investigation of the interrelationships between motivation, engagement, and complex problem solving in game-based learning. Educational technology \& society 17,1 (2014), 42-53.

[45] Miriam Evans and Alyssa R Boucher. 2015. Optimizing the power of choice Supporting student autonomy to foster motivation and engagement in learning. Mind, Brain, and Education 9, 2 (2015), 87-91.

[46] M Aliv Faizal. 2016. The effects of conversation-gambits visual-novel game on students' English achievement and motivation. In 2016 International Electronics Symposium (IES). IEEE, 481-486.

[47] Clara Fernández Vara. 2009. The tribulations of adventure games: integrating story into simulation through performance. Ph.D. Dissertation. Georgia Institute of Technology.

[48] Todorka Alexandrova Francisco Lepe Salazar, Tatsuo Nakajima. 2013. Visual Novels: An Methodology Guideline for Pervasive Educational Games that Favors Discernment. Grid and Pervasive Computing Lecture Notes in Computer Science (2013), 234-243.

[49] Alex Frazer, David Argles, and Gary Wills. 2007. Is less actually more? The usefulness of educational mini-games. In Seventh IEEE International Conference on Advanced Learning Technologies (ICALT 2007). IEEE, 533-537.

[50] Jana Fruth, Carsten Schulze, Marleen Rohde, and Jana Dittmann. 2013. Elearning of IT security threats: A game prototype for children. In IFIP international conference on communications and multimedia security. Springer, 162-172.

[51] Pedro Gabriel, Tsukasa Hirashima, and Hayashi Yusuke. 2018. A Serious Game for Improving Inferencing in the Presence of Foreign Language Unknown Words. International fournal of Advanced Computer Science and Applications 9, 2 (2018) https://doi.org/10.14569/ijacsa.2018.090202

[52] Stefan Göbel and Florian Mehm. 2013. Personalized, adaptive digital educational games using narrative game-based learning objects. In Serious Games and Virtual Worlds in Education, Professional Development, and Healthcare. IGI Global, 74-84.
[53] David Gouveia, António Andrade, Paula Escudeiro, and Carlos Vaz De Carvalho. 2014. Skill and Competence Development Through Games. In Proceedings of the 16th International Conference on Information Integration and Web-based Applications \& Services. 49-53.

[54] Rania Hodhod, Paul Cairns, and Daniel Kudenko. 2011. Innovative integrated architecture for educational games: challenges and merits. In Transactions on edutainment $V$. Springer, 1-34.

[55] Rania Hodhod, Daniel Kudenko, and Paul Cairns. 2009. AEINS: Adaptive Educational Interactive Narrative System to Teach Ethics.. In AIED 2009: 14th International Conference on Artificial Intelligence in Education Workshops Proceedings. 79.

[56] Robin Hunicke, Marc Leblanc, and Robert Zubek. 2004. MDA: A formal approach to game design and game research. In In Proceedings of the Challenges in Games AI Workshop, Nineteenth National Conference of Artificial Intelligence. Press, 1-5.

[57] Duy Huynh, Phuc Luong, Hiroyuki Iida, and Razvan Beuran. 2017. Design and Evaluation of a Cybersecurity Awareness Training Game. Entertainment Computing - ICEC 2017 Lecture Notes in Computer Science (2017), 183-188. https://doi.org/10.1007/978-3-319-66715-7_19

[58] Ana Isabel Illanas, Francisco Gallego, Rosana Satorre, and Faraón Llorens. 2008. Conceptual mini-games for learning. In International Technology, Education and Development Conference (INTED).

[59] Chaima Jemmali, Sara Bunian, Andrea Mambretti, and Magy Seif El-Nasr. 2018. Educational Game Design: An Empirical Study of the Effects of Narrative (FDG '18). Association for Computing Machinery, New York, NY, USA, Article Article 34, 10 pages. https://doi.org/10.1145/3235765.3235783

[60] Vincent Jonker, Monica Wijers, and Frans Van Galen. 2009. The motivational power of mini-games for the learning of mathematics. In Third European Conference on Gamebased Learning (ECGBL). 202-210.

[61] Kristine Jørgensen. 2011. Time for New Terminology?: Diegetic and NonDiegetic Sounds in Computer Games Revisited. In Game sound technology and player interaction: Concepts and developments. IGI Global, 78-97.

[62] Kristine Jrgensen. 2007. On transdiegetic sounds in computer games. Northern Lights: Film \& Media Studies Yearbook 5, 1 (2007), 105-117.

[63] Idit Katz and Avi Assor. 2007. When choice motivates and when it does not. Educational Psychology Review 19, 4 (2007), 429.

[64] Mansureh Kebritchi et al. 2008. Examining the pedagogical foundations of modern educational computer games. Computers \& Education 51, 4 (2008), $1729-1743$.

[65] Oleksandra Keehl and Edward Melcer. 2019. Radical tunes: exploring the impact of music on memorization of stroke order in logographic writing systems. In Proceedings of the 14th International Conference on the Foundations of Digital Games. 1-6.

[66] Michael D Kickmeier-Rust, Stefan Göbel, and Dietrich Albert. 2008. 80Days: Melding adaptive educational technology and adaptive and interactive storytelling in digital educational games. In Proceedings of the First International Workshop on Story-Telling and Educational Games (STEG'08). 8.

[67] Erica Kleinman, Elin Carstensdottir, and Magy Seif El-Nasr. 2019. A Model for Analyzing Diegesis in Digital Narrative Games. Interactive Storytelling Lecture Notes in Computer Science (2019), 8-21. https://doi.org/10.1007/978-3-03033894-7_2

[68] Tanja Korhonen and Raija Halonen. 2017. On the development of serious games in the health sector-A case study of a serious game tool to improve life management skills in the young. In International Conference on Enterprise Information Systems, Vol. 2. SCITEPRESS, 135-142.

[69] Max Kreminski, Ben Samuel, Edward Melcer, and Noah Wardrip-Fruin. 2019. Evaluating AI-based games through retellings. In Proceedings of the AAAI Conference on Artificial Intelligence and Interactive Digital Entertainment, Vol. 15. 45-51.

[70] Daniel Kromand. 2008. Sound and the diegesis in survival-horror games. Audio Mostly 2008 (2008).

[71] Carol C Kuhlthau, Leslie K Maniotes, and Ann K Caspari. 2015. Guided inquiry: Learning in the 21st century: Learning in the 21st century. Abc-Clio.

[72] Liting Kway and Alex Mitchell. 2018. Emotional agency in storygames. Proceedings of the 13th International Conference on the Foundations of Digital Games FDG 18 (2018). https://doi.org/10.1145/3235765.3235777

[73] Petros Lameras, Sylvester Arnab, Ian Dunwell, Craig Stewart, Samantha Clarke, and Panagiotis Petridis. 2017. Essential features of serious games design in higher education: Linking learning attributes to game mechanics. British journal of educational technology 48, 4 (2017), 972-994.

[74] Lev N Landa. 1983. Landamatics Instructional Design Theory and. Instructionaldesign theories and models: A new paradigm of instructional theory 2 (1983), 341.

[75] Diana Laurillard. 2009. The Pedagogical Challenges to Collaborative Technologies. International fournal of Computer-Supported Collaborative Learning 4 (03 2009), 5-20. https://doi.org/10.1007/s11412-008-9056-2

[76] Richard Lee and Gabriel Chia. 2015. Surfacing Intuitions Through Visual Novels. In Disciplinary Intuitions and the Design of Learning Environments. Springer, 145-153. 
[77] Seung Y Lee, Jonathan P Rowe, Bradford W Mott, and James C Lester. 2013. A supervised learning framework for modeling director agent strategies in educational interactive narrative. IEEE Transactions on Computational Intelligence and AI in Games 6, 2 (2013), 203-215.

[78] Nadia Rowena C Leetian, Ma Regina E Estuar, and Michael B Syson. 2013. Designing Mobile Educational Games on Voter's Education: A Tale of Three Engines. International fournal of e-Education, e-Business, e-Management and e-Learning 3, 5 (2013), 357.

[79] Duane Lemley, Richard Sudweeks, Scott Howell, R Dwight Laws, and Octavia Sawyer. 2007. The effects of immediate and delayed feedback on secondary distance learners. Quarterly Review of Distance Education 8, 3 (2007), 251.

[80] James C Lester, Jonathan P Rowe, and Bradford W Mott. 2013. Narrativecentered learning environments: a story-centric approach to educational games. In Emerging Technologies for the Classroom. Springer, 223-237.

[81] Kenneth Lim. 2009. The six learnings of Second Life: A framework for designing curricular interventions in-world. Fournal For Virtual Worlds Research 2, 1 (2009).

[82] Craig A. Lindley. 2005. Story and narrative structures in computer games In Developing Interactive Narrative Content, Brunhild Bushoff (Ed.). HighText Verlag, Munich.

[83] Brian Magerko. 2007. Evaluating preemptive story direction in the interactive drama architecture. Fournal of Game Development 2, 3 (2007), 25-52.

[84] Sana Maqsood, Christine Mekhail, and Sonia Chiasson. 2018. A day in the life of jos: a web-based game to increase children's digital literacy. In Proceedings of the 17th ACM Conference on Interaction Design and Children. 241-252.

[85] Chris Martens and Matthew A. Hammer. 2017. Languages of Play: Towards Semantic Foundations for Game Interfaces. In Proceedings of the 12th International Conference on the Foundations of Digital Games (FDG '17). ACM, New York, NY, USA, 32:1-32:10. https://doi.org/10.1145/3102071.3102096

[86] Michael Mateas and Andrew Stern. 2005. Structuring Content in the Facade Interactive Drama Architecture (AIIDE'05). AAAI Press, 93-98.

[87] Hilary McLellan. 2007. Digital storytelling in higher education. Fournal of Computing in Higher Education 19, 1 (2007), 65-79.

[88] Edward F Melcer and Marjorie Ann M Cuerdo. 2020. Death and Rebirth in Platformer Games. In Game User Experience And Player-Centered Design. Springer.

[89] Edward F Melcer, Katelyn Grasse, James Ryan, Nick Junius, Max Kreminski, Dietrich Squinkifer, Brent Hill, and Noah Wardrip-Fruin. 2020. Getting Academical: A Choice-Based Interactive Storytelling Game for Teaching Responsible Conduct of Research. In Proceedings of the 15th International Conference on the Foundations of Digital Games - FDG 20.

[90] Edward F Melcer and Katherine Isbister. 2016. Bridging the physical divide: A design framework for embodied learning games and simulations. In Proceedings of the 2016 CHI Conference Extended Abstracts on Human Factors in Computing Systems. 2225-2233.

[91] Edward F Melcer and Katherine Isbister. 2018. Bots \& (Main) frames: exploring the impact of tangible blocks and collaborative play in an educational programming game. In Proceedings of the 2018 CHI Conference on Human Factors in Computing Systems. 1-14.

[92] Edward F Melcer, James Ryan, Nick Junius, Max Kreminski, Dietrich Squinkifer Brent Hill, and Noah Wardrip-Fruin. 2020. Teaching Responsible Conduct of Research Through an Interactive Storytelling Game. In Proceedings of the 2020 CHI Conference Extended Abstracts on Human Factors in Computing Systems.

[93] David E. Millard, Charlie Hargood, Michael O. Jewell, and Mark J. Weal. 2013 Canyons, deltas and plains: towards a unified sculptural model of location-based hypertext. In Proceedings of the 24th ACM Conference on Hypertext and Social Media. ACM, 109-118.

[94] Cristina Hava Muntean, Nour El Mawas, Michael Bradford, and Pramod Pathak. 2018. Investigating the impact of an immersive computer-based math game on the learning process of undergraduate students. In 2018 IEEE Frontiers in Education Conference (FIE). IEEE, 1-8.

[95] Janet Murray. 2005. Did It Make You Cry? Creating Dramatic Agency in Immersive Environments. Lecture Notes in Computer Science Virtual Storytelling. Using Virtual Reality Technologies for Storytelling (2005), 83-94. https: //doi.org/10.1007/11590361_10

[96] David Neumeyer. 2009. Diegetic/Nondiegetic: A Theoretical Model. Music and the Moving Image 2, 1 (2009), 26-39.

[97] James Niehaus and Mark O Riedl. 2009. Scenario adaptation: An approach to customizing computer-based training games and simulations. In Proceedings of the AIED 2009 Workshop on Intelligent Educational Games, Vol. 3. 89-98.

[98] Supeno Mardi Susiki Nugroho, Angga Surya Utama, Mochamad Hariadi, Umi Laili Yuhana, and Mauridhi Hery Purnomo. 2018. HEIRDOM: Multiple Ending Scenario Game For Mathematics Learning Using Rule-Based System. 2018 International Conference on Computer Engineering, Network and Intelligent Multimedia (CENIM) (2018). https://doi.org/10.1109/cenim.2018.8711022

[99] Supeno Mardi Susiki Nugroho, Angga Surya Utama, Mochamad Hariadi, Umi Laili Yuhana, and Mauridhi Hery Purnomo. 2018. HEIRDOM: Multiple Ending Scenario Game For Mathematics Learning Using Rule-Based System. In 2018 International Conference on Computer Engineering, Network and Intelligent
Multimedia (CENIM). IEEE, 192-197.

[100] Kimmo Oksanen, Jan Van Looy, and Frederik De Grove. 2013. Avatar identification in serious games: the role of avatar identification in the learning experience of a serious game. 3 .

[101] Dan O’Brien, Kimberly A Lawless, and PG Schrader. 2010. A taxonomy of educational games. In Gaming for classroom-based learning: Digital role playing as a motivator of study. IGI Global, 1-23.

[102] Natalia Padilla-Zea, Francisco L Gutiérrez, José Rafael López-Arcos, Ana AbadArranz, and Patricia Paderewski. 2014. Modeling storytelling to be used in educational video games. Computers in Human Behavior 31 (2014), 461-474.

[103] Jan L Plass, Bruce D Homer, Charles Kinzer, J Frye, and Ken Perlin. 2011. Learning mechanics and assessment mechanics for games for learning. G4LI White Paper 1 (2011), 2011

[104] Mark Riedl and Vadim Bulitko. 2012. Interactive narrative: A novel application of artificial intelligence for computer games. In Twenty-Sixth AAAI Conference on Artificial Intelligence.

[105] Mark O Riedl, Andrew Stern, Don Dini, and Jason Alderman. 2008. Dynamic experience management in virtual worlds for entertainment, education, and training. International Transactions on Systems Science and Applications, Special Issue on Agent Based Systems for Human Learning 4, 2 (2008), 23-42.

[106] Irvin Rock. 1958. Repetition and learning. Scientific American 199, 2 (1958), 68-76.

[107] Jonathan Rowe and James Lester. 2015. Improving Student Problem Solving in Narrative-Centered Learning Environments: a Modular Reinforcement Learning Framework. 419-428. https://doi.org/10.1007/978-3-319-19773-9 42

[108] Jonathan P Rowe and James C Lester. 2010. Modeling user knowledge with dynamic Bayesian networks in interactive narrative environments. In Sixth Artificial Intelligence and Interactive Digital Entertainment Conference.

[109] Jonathan P Rowe, Lucy R Shores, Bradford W Mott, and James C Lester. 2010. A framework for narrative adaptation in interactive story-based learning environments. In Proceedings of the Intelligent Narrative Technologies III Workshop. $1-8$.

[110] Jonathan P Rowe, Lucy R Shores, Bradford W Mott, and James C Lester. 2011. Integrating learning, problem solving, and engagement in narrative-centered learning environments. International fournal of Artificial Intelligence in Education 21, 1-2 (2011), 115-133.

[111] Marie-Laure Ryan. 2009. From Narrative Games to Playable Stories: Toward a Poetics of Interactive Narrative. StoryWorlds: A Journal of Narrative Studies 1, 1 (2009), 43-59. https://doi.org/10.1353/stw.0.0003

[112] Francisco Lepe Salazar, Tatsuo Nakajima, and Todorka Alexandrova. 2013. Visual Novels: An Methodology Guideline for Pervasive Educational Games that Favors Discernment. In International Conference on Grid and Pervasive Computing. Springer, 234-243.

[113] Tom Schaul. 2013. A video game description language for model-based or interactive learning. In 2013 IEEE Conference on Computational Inteligence in Games (CIG). IEEE, 1-8.

[114] Eline Sierens, Maarten Vansteenkiste, Luc Goossens, Bart Soenens, and Filip Dochy. 2009. The synergistic relationship of perceived autonomy support and structure in the prediction of self-regulated learning. British fournal of Educational Psychology 79, 1 (2009), 57-68.

[115] Peter A Smith and Alicia Sanchez. 2010. Mini-games with major impacts. In Serious game design and development: Technologies for training and learning. IGI Global, 1-12.

[116] Qiulian Song, Ling He, and Xiaoqiang Hu. 2012. To improve the interactivity of the history educational games with digital interactive storytelling. Physics Procedia 33 (2012), 1798-1802.

[117] Ulrike Spierling. 2008. 'Killer Phrases': Design Steps for a Game with Digital Role-Playing Agents. In Transactions on edutainment I. Springer, 150-161.

[118] Rand Spiro, Richard Coulson, Paul Feltovich, and Daniel Anderson. 2013. Cognitive Flexibility Theory: Advanced Knowledge Acquisition in Ill-Structured Domains. Theoretical Models and Processes of Reading (Jul 2013), 544-557. https://doi.org/10.1598/0710.22

[119] Dean Sullivan and Jessica Critten. 2014. Adventures in Research: Creating a video game textbook for an information literacy course. College \& Research Libraries News 75, 10 (2014), 570-573.

[120] Dagar V and Yadav A. 2016. Constructivism: A Paradigm for Teaching and Learning. Arts and Social Sciences fournal 7, 4 (2016). https://doi.org/10.4172/ 2151-6200.1000200

[121] Pengcheng Wang, Jonathan Rowe, Bradford Mott, and James Lester. 2016. Decomposing drama management in educational interactive narrative: A modular reinforcement learning approach. In International Conference on Interactive Digital Storytelling. Springer, 270-282.

[122] Scott Watson, Natalie Vannini, Megan Davis, Sarah Woods, Marc Hall, Lynne Hall, and Kerstin Dautenhahn. 2007. FearNot! an anti-bullying intervention: Evaluation of an interactive virtual learning environment. Artificial Intelligence and Simulation of Behaviour (AISB), April 24 (2007)

[123] Sebastian A Weiß and Wolfgang Müller. 2008. The potential of interactive digital storytelling for the creation of educational computer games. In International 
Conference on Technologies for E-Learning and Digital Entertainment. Springer, $475-486$.

[124] Jui-Feng Weng, Hsiu-lien Kuo, and Shian-Shyong Tseng. 2011. Interactive storytelling for elementary school nature science education. In 2011 IEEE 11th International Conference on Advanced Learning Technologies. IEEE, 336-338.

[125] Pieter Wouters, Erik D. Van Der Spek, and Herre Van Oostendorp. 2009. Current Practices in Serious Game Research. Games-Based Learning Advancements for Multi-Sensory Human Computer Interfaces (2009), 232-250. https://doi.org/10. 4018/978-1-60566-360-9.ch014

[126] Will Wright and Ian Bogost. 2007. Persuasive games: The expressive power of videogames. Mit Press.

[127] Shingo Yamaguchi and Yoshiko Tamura. 2017. Modeling of stalkers' behavior and development of simulated experience game for education. In 2017 IEEE 6th Global Conference on Consumer Electronics (GCCE). IEEE, 1-4.

[128] Langxuan Yin, Lazlo Ring, and Timothy Bickmore. 2012. Using an interactive visual novel to promote patient empowerment through engagement. Foundations of Digital Games 2012, FDG 2012 - Conference Program, 41-48. https://doi.org/ $10.1145 / 2282338.228235$
[129] Amri Yusoff, Richard Crowder, Lester Gilbert, and Gary Wills. 2009. A conceptual framework for serious games. In 2009 Ninth IEEE International Conference on Advanced Learning Technologies. IEEE, 21-23.

[130] Zarwina Yusoff, Amirrudin Kamsin, Shahaboddin Shamshirband, and Anthony T Chronopoulos. 2018. A survey of educational games as interaction design tools for affective learning: Thematic analysis taxonomy. Education and Information Technologies 23, 1 (2018), 393-418.

[131] Lei Zhang, Doug A Bowman, and Caroline N Jones. 2019. Exploring Effects of Interactivity on Learning with Interactive Storytelling in Immersive Virtua Reality. In 2019 11th International Conference on Virtual Worlds and Games for Serious Applications (VS-Games). IEEE, 1-8.

[132] Michal Zion and Ruthy Mendelovici. 2012. Moving from structured to open inquiry: Challenges and limits. Science Education International 23, 4 (2012), 383-399.

[133] Alexander Zook, Stephen Lee-Urban, Mark O Riedl, Heather K Holden, Robert A Sottilare, and Keith W Brawner. 2012. Automated scenario generation: toward tailored and optimized military training in virtual environments. In Proceedings of the international conference on the foundations of digital games. 164-171. 